\title{
MUJER AUSENTE, LIRISMO AGUDO
}

Las más acuciosas pesquizas no han logado todavía ubicar a la mujer en la literatura peruana prerromántica. No obstante de que la tradición refiere que la Colonia fué una época de galantería y pispiriteo, nada hay en la literatura que trasluzca delicadeza, erotismo. A lo sumo, cierta forzada admiración ante las bellezas femeninasque no se precisan- como las que aparecen en la Mitología grecorromana. $Y$, sin embargo, la Tradición recoge la fama de una edad galante, en que mozas de trapío y linajudas damas lucieron donaire, coquetería, seducción, belleza y lisura.

Parece, al juzgariel lcontenidg femenino de la. literatura peruana prerromántica, que la mujer hubiese vivido ausente de la vida de los escritores y que, por consiguiente, -1os casos déeAmarilis y la "Limana Musa", doria Josefa de Carrillo y Sotomayor, hubiesen constituido, más que casos de femenil sensibilidad y conatos de Safos, nada más que nuncios de feminismo galopante y pankhurstiano. Pero, al seguir más de cerca el fenómeno, que tan definitiva y tristemente condenaría a los peruanos pre 1815, se olvida que la literatura traduce quizás más que hechos, anhelos; de modo que, a través de las obras literarias de una época o un país, se advierte tanto lo que hicieron como lo que desearon por lo menos sus grupos intelectuales. De tal manera resulta llevadera la teoría, según la cual Rubén Darío fué un poeta típica y representativamente americano, ya que el parisianismo de sus versos, no traduce sino la ilusión que por París, meta de muchos sueños truncos, tuvieron varias generaciones del sur de Río Grande; y se explica uno, leyendo los versos de Felipe Pardo, que en el Perú hubo en aquel tiempo, no un moviminto monarquista y antidemocrático profundo y definido, sino una tendencia así, mientras la realidad era demagógica y caudilleril; que el medio peruano en el 890 no era radicál y anticlerical, como se trasluce en las obras de González Prada, sino precisamente la de éste fué una reacción 
violenta y minoritaria contra la presión del conservadorismo y el tradicionalismo que eran las realidades circunstantes; que Valdelomar, lejos de haber vivido de un medio de distinción wildeana, insurgía contra el criollismo ambiente. Y Wilde mismo se levanta sobre su miseria, cuando en "La Balada de la cárcel de Reading" y en "De Profundis" olvida la tragedia del C. 33 para no ver sino la infinita desventura del hombre a quien ajusticiaron cerca de él, y el alma que se hundía en la desesperación dentro de sí misma, mientras el artista sólo era espectador de su propia tragedia.

\section{Discrepancia}

Comenta Laló en "L'Art et la Vie Sociale", que los cantores árabes que recorrian los cafés recitando fragmentos de las "Mil y una noches" cumplían una función social, toda vez que dentro de las sociedades poligámicas, la función sexual tiende a circunscribirse a los que pueden sostener el lujo de un harem, es decir un tren de mujeres para su egoista uso; y dentro de esa condición, existe en los dernás un ansia infinita de voluptuosidad que se revela y se sacia con relatos escabrosos, escatológicos. Algo más: la clausura del harem restringe el conocimiento de la mujer a las propias, de modo que, espoleada la imaginación por la ausencia de otras que sirvan de término de comparación, el árabe desataba su fantasía para imaginar beldades ocultas, ignoradas. La mujer gue tántos delirios provoca en la literatura árabe no es, sin embargo, nifácil, Cnifominadora. Por el contrario, está avasallada y distamte. PLacriodeañ Cemucessyula domina el señor. Verdaderamente - sin apelar a "Las Desacreditadas" o "Desencantadas" de Pierre Loti- la literatura arábiga nos hace soñar en una vida en que la mujer triunfa, manda, impera y es infinitamente asequible y voluptuosa; pero, la realidad es que la mujer triunfa, sí, pero en la imaginación, y sólo una virtualidad de placer, un deseo contenido de voluptuosidad es lo que alienta tales deliquios poemáticos.

En cambio, la Edad Media es diferente;- y Finke nos ofrece un discreto cuadro de ello en "La Mujer de la Edad Media", al citar la opinión del romanista G. Grober quen escribe:

"No obstante todo el culto caballeresco y la idealización de que fué objeto la mujer, el hombre medioeval no vió en ella más que un ser ineducable, voluble, incalculable en sus determinaciones y dominado por malas disposiciones; un ser que ha de someterse al hombre y que solamente para el hombre existe; el hombre medioeval vió en la mujer la Eva del Viejo Testamento, la que 
hizo caer al hombre en el pecado, y sin la cual, no habiéndose interrumpido la santidad de Adán, no hubiera sido necesaria la Redención".

Finke, o. c., Md. "Rev. de Occ", Madrid, p. 114.

Tal respecto aparente, literario por decir mejor, es tal, que el propio Finke observa que, después de recorrer "centenares de sermones, impresos y manuscritos", le ha sido imposible "sacar de ellos la conclusión de que se menospreciaba a la mujer". (p. 126). En otro lugar, sin embargo, apunta que la aparición de la cultura laica acentúa la oposición entre el amor a la mujer y el amor a Dios; que el placer sensual se afirma con valor propio; las mujeres toman parte en la sociabilidad y como reflejo de este movimiento, para el cual la orientación teológica es antinatural, surge la poesía amorosa, es decir, surge la lírica. El tema de esta lírica nueva, después del prolongado silencio en el cual dominó la nota épica- signo de dominación masculina, según Laló- es la mujer; pero, "en el mayor número de los casos o con mucha frecueneia, por lomenos, la mujer que se festeja no es la propia" (p. 4-66) Mus adelante observará que "el amor gue cantan el Dante y sus cuntemporáneos excluye el matrimonio propiamente dicho. La esposa en la mayor parte de los casos, queda fuera del horizonte literatio" (130) Entonces, junto al homenaje feudal a la dama, surge la canción al amor lejano, como en Jaufre Rucicl, poeta ciel siglo XIII.

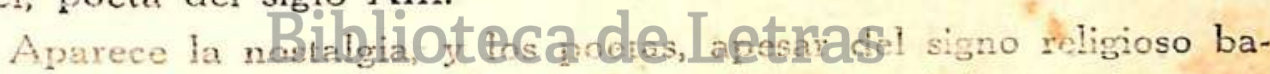
jo el cual viven, ajorgepeiceinefli Converson tiento, sin cesar, como es fácil observar en Villon prótongéndose Lata Verlaine, en quien una vez más se reproduce el proceso infinito de la Edad Media, como en sui ingenuo elogio à la edad "cnorme et delicat", que bien pudo amparax su misticismo desviado.

El lirismo que así surgía, ponía fin a la etapa de predominio epicista. En la epopeya, el poeta alababa al guerrero, no al amor; si se refería a la unión de hombres y mujeres, el interés del poeta, y seguramente del pueblo en gestación, iba en pos de las nupcias, no del amor mismo. La relación conyugal es lo que importa: la esposa, fiel como Penélope o infiel como Helena, inspira los cantos épicos. Sentimiento disociador, el amor queda desterrado de sociedades en pugna, y los escandinavos castigaban severamente a los Minnesinger alemanes que entonaban cantos de amor.

Ch. Lalo, L'Art et la Vie Sociale, Paris, 1921, p. 182 y sig.

Pero, cuando, como anota Finke, la cultura laica concela el predominio religioso amparador de la epopeya y la teología; empiezan a cantar los trovadores, troveres, Minnessinger, juglares; y cantan al 
amor; a la mujer, cuya situación se idealiza por su misma condición de sometida a la autoridad inapelable y despótica del marido. En la poesía provenzal, la más caballeresca de todas y la más idealista, se explota este contraste, aparentemente sin consonancia con las rudas costumbres de entonces, época de cinturón de castidad y de señores de horca y cuchilla, de la Leyenda de Barba Azul y de las pasiones broncas del Romancero; y en que, de acuerdo con la observación de Laló, "el arte se vuelve (entonces) el complemento y aún la antitesis de la vida, en nombre de un ideal cualquiera". (p. 195).

Ya Richard, recalcando la importancia de la mujer en la literatura árabe, anota que:

"En el harem musulmán como en la familia hindú o china, es entendido que la cultura estética no existe sino para los hombres, y a lo sumo para algunas mujeres sostenidas fuera de la familia, como las bayaderas, cortesanas y danzarinas sagradas".

Richard, La femme dans lhistoire, Paris, 1909, p. 338.

Tan cierta resulta la situación antitética, y hasta contradictoria entre la literatura y los hechos- decir "la vida", me parece falso y presuntuoso, porque la vida no sólo comprende hechos, sino también aspiraciones y mucho más- que en el ambiente del Romancero español se advierte la aspiración de todos a la lealtad. Los personajes juran fidelidad, y se jactan de altos linajes y de seyeridad para cumplir su palabra. Pero, enl derredor del Câ, difíilmente crece la lealtad,

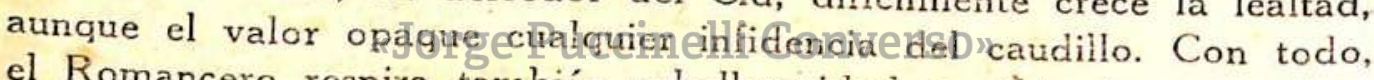
el Romancero respira tambićn caballerosidad y cièrta bronca galantería: la más delicada es de moros, musulmanes, gentes de harem y Korán. A Lanzarote - cuenta el Romance- le halagaban, como siervas, Princesas; a su caballo, doncellas; y a modo de homenaje y plei-
tesía,

la linda reina Ginebra

se lo acostaba consigo.

Este compartir tan liso y llano del lecho de la Reyna Ginebra, está reñido con la galantería, quizás, porque el autor del romance no padecía de la sed voluptuosa de los musulmanes invasores; y porque la dama, la señora, tenía un papel predominante en una sociedad entregada a la guerra, y en la que a ella le tocaba custodiar el hogar. Tampoco se exacerbaba el misticismo, aunque regía la devoción. El misticismo y el ascetismo florecieron después, en la paz, en la riqueza, como contraste con el holgorio ambiente. Con el misticisno, la galantería no se afinó. Se volvió digna, hogareña. En las sociedades de insatisfechos sentidos, de oligarquías poligámicas o de severa monoga- 
mia, floreció la galantería quintasenciada: el Renacimiento, todo pecado; el Japón, todo autoridad. Con una diferencia; que en el primero, la mujer, no la esposa, tuvo un papel señero; y en el segundo, insignificante.

\section{Nuestro caso}

Niestro virreinato vivió una historia especial. Desde la iniciación de la Conquista, advirtieron los observadores la ausencia de mujeres blancas, es decir, de compañeras: hubo la sierva, la conquistada, la sometida, pero los sojuzgadores carecían de delicadeza, de nuances, para alquitarar aquella dominación. $Y$ el clima hizo una jugarreta al conquistador, pues le esclavizó los sentidos, y la sierva se trocó en tiranuela. Cada vez más se alejaba el reinacio de la.galantería quintaesenciada a la manera petrarquesca.

Y tenía que ser así. Las "Leyes de Indias", fiel expresión del pensamiento español ante el fenómeno de la conquista y el coloniaje, prohibieron perentoriamente que ninguna mujer soltera pudiese emigrar de España con rumbo a América; por lo que Blanco Fombona se lamenta: "como iban pócas mujeres de España, el amor de la mujer falta en la epopeya". Esas "pocas mujeres" vinieron tarde y en escasísimo númerol Inés Mệz, cempanterảade Martinez de Alcántara, y doña Inés Byayg de Laghnasiı eøposa de Nicolás de Ribera el Mozo, fueron las primeras hembras peninsulares que desembarcarón en tierras peruanas. El Primer virrey que vino $\mathrm{cg}$ a su esposa, fué sólo el octavo, don García Hurtado de Mendoza: el cuarto, Conde de Nieva andaba a la caza de corazones hospitalarios: y murió en ello.

Leyes de Indias, Ib. tit. XXV, Leyes XVII- XXI.

Blanco Fombona, El Conquistador español del siglo XVI, Madrid, 1922, p. 265.

L. A. Sánchez, La Literatura Peruana, Lima, 1928 t. 1,- p. $96-98$.

Y todo este cuadro sintomático tiene una enorme repercusión en la literatura. Los españoles a pesar de no traer mujeres de su raza, sino mucho más tarde, no padecieron la urgencia carnal, la exacerbación de los sentidos que en el árabe produce cantos voluptuosos. El Inca Garcilaso nació, de materna sangre real, en 1539; y antes había nacido, de materna y esclarecida sangre americana, el P. Blas de $\mathrm{Va}$ lera. Se poblaba de mestizos el vivaque conquistador. Los cholitos aprendían romances españoles, romances de guerra. Las hembras sumisas aplacaban los ardores de los guerreros, o se refugiaban, como Isabel Chimpu Ocllo, en orgulloso y dolido apartamiento. 
El mestizaje en el campo fué fácil, bonancible. Los soldados se acomodaban al yivir local. Juan de Betanzos no tuvo reparos en aceptar las migajas de amor de Francisco Pizarro, y se adaptó al vivir, pensar y hablar de su mujer, de cuya unión nació la "Suma y Narración de los Incas". En cambio, en la ciudad principal, la cohabitación se realizaba, pero más humillante para la víctima. El "viracocha" exigía amor, atención, pleitesía, $y$, en cambio, a duras penas concedía mesa. L.echo, sí, pero compartido. Confidencias, jamás. En trescientos años, las dos razas, española e indígena, vivieron incomunicadas, pese al tratamiento diario. La negra fué más ladina, lo mismo que el negro. Ganaron confidencia y voluptuosidad. Y así anduvo desatada y sin muchas trabas la pasión carnal, mientras el señor se dignaba visitar a sus ciervas, y a veces, la señora sucumbía a la tentación. (El caso de "Matalaché" no es caso único). Las crónicas coloniales recogen algunos datos de esta fácil cohabitación. Así, por ejemplo, se sabe que el Inquisidor Francisco de la Cruz mezcló su sangré- y lo pagó con la vida - con el de una linajuda familia limeña, por cuyo motivo fué condenado, por la propia Inquisición, a la hoguera.

Medina, El Santo Oficio de la Inquisición en Lima, Santiago, 1887, t. I, p. $57-60 ; 63$ y sig.

Palma, Anales de la Inquisición en Lima, Lima, 1863, reed. "Apendice a mis ult. tradiciones", Barcelona, p. 351.

En la sabrosa crónica de los Mugaburu encuentro este otro dato, no sintomático, pero, si, curioso y revelador: el del "gran hereje", "gran perro, lujurioso. Ideshentesco'a camelitat Fa César Pasani Be-

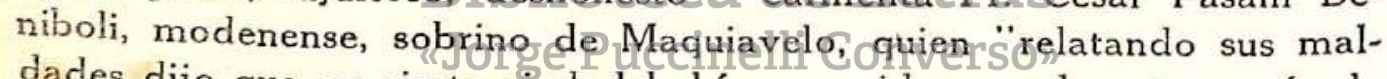
dades dijo que en cierta ciudad había conocido carnalmente a más de trescientas y sesenta mujeres" (1667).

Mugaburu, Diario de Lima, ed. Urteaga-Romero, Lima, 1917 , t. I. p. 137.

Algún gérmen de desmoralización habría, pues, cuando el grave las disposiciones que permitían el viaje de las mujeres españolas a América, en seguimiento de sus maridos, porque "no pueden separar se ni privarse voluntariamente de su cohabitación"; y sobre todo, "de la costumbre de echar vandos y pregones generales, para que todos vengan a declarar, y descubrir a los que supieren que residen en ellas sin sus mugeres, y resuelve que los que los conosieren, están obligados a declararlos, y si sobre esto se pusieren en censuras, incurren en ellas, sino los delatan, porque miran al bien común".

Solózarno, Política Indiana, Madrid, 1648.-Lb. V, e. V. p. 792 , col. $1^{\circ}$. 
Existía, por consiguiente, cierto relajamiento, contra el que poco lograban los bandos, Reales Cédulas, Bulas, etc. La facilidad del amor, no favorecía al ascetismo. De ahí que, a pesar del número de iglesias y religiosos, nuestro virreinato resultó devoto y no místico. Toribio de Mogrovejo fué un reformador, santo dinámico. El beato Martín, caridad y modestia.

Los mismos virreyes no favorecían la rectitud de costumbres. Por uno severo, el de Lemos, de quien se contaban algunas aventuras en Italia, surgen el enamorado Conde de Nieva, víctima de sus amoríos, y el de Esquilache, galanteador y piropero; y, muchos más tarde, salvando la gama de tántos otros, el más célebre de todos, por obra de amor ilegal y a mestiza, don Manuel de Amat. Y no se diga que hay leyenda y fantasía en todo ello, puesto que hasta lo referente al de Nieva está esclarecido, como lo observa Riva Aguero en su admirable prólogo, por los bandos publicados en el tomo titulado "La Audiencia de Lima".

Riva Aguero, Prólogo a "La Audiencia de Lima", publicada por D. Roberto Levillier, Madrid, 1922. p. LXXI.

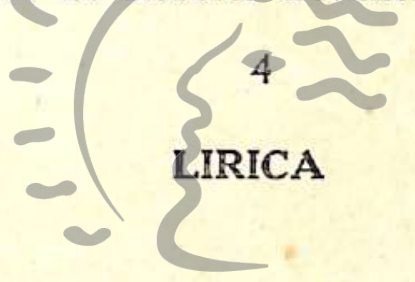

Dentro de una sociedad en que el amor se presentaba sin complicaciones, y tan fádilmente lograba el Chombse de España aplacar

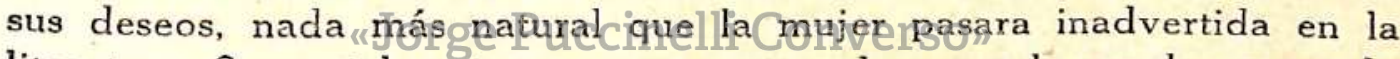
literatura. Se cantaban temas que preocupaban por lo agudos o por lo anhelados. Era el caso de repetir las palabras atribuidas a Demóstenes contra la hetaira Neera; "tenemos hetairas para el placer, esposas para tener hijos legítimos y guardianes de confianza en casa". Aquí había que reemplazar el vocablo "hetairas" por siervas, indias, mulatas, negras, mestizas. A fines del siglo XVII, el poeta criollo Caviedes reflejaba la predilección por las mestizas y el desdén por las españolas, en estos versos, que constituyen la introducción de la mulata en nuestras letras:

Manda que las españolas, del más hermoso primor vendan a real la esperanza y a cuatro la posesión.... ....Manda, pues, que las mestizas que revendedoras son, den ocho onzas de maíz por peso de un real de amor.... 
...Manda que las cuarteronas

tengan sin tasa el valor,

porque todo lo trigueño

anda caro el día de hoy....

....Manda que negras e indias

pues harto bellacas son,

valgan el precio que quieran

de palo, patada o coz....

Caviedes, Diente del Parnaso, Lima 1899, en vol. "Flor de Academias, p. 444.

Para el mestizo Caviedes solo valian ya las trigueñas, las mulatas; negras e indias- ensueño del conquistador- no lo eran del virrey. Así Amat daría la razón a Caviedes setenta años més tarde; pero, desde 1680 cuando, a pesar de la relajación, existía cierto control, y cuando sobre todo, la mestiza se daba a desear, aparece el primer poeta lírico-erótico, que, por seguir al la gente culta- mestizo al cabo- se alambicó enseguida.

Caviedes, en pleno ocaso del seiscientos, recoge la tradición galante de los dominadores, se apropia de ella pero para cantar a los mestizos, su propia raza. Y al convextir a la mujer en tema de poesía no logra libertarse de la influencia de los señores. Cierto que trasunta el poderío de Quevedo, maestro de cuantos intentaron seguir la senda popular. Pero, al revés de Quevedo, rinde pleitesía al culteranismo que ya había amanecido en la literatura colonial. Su galan-

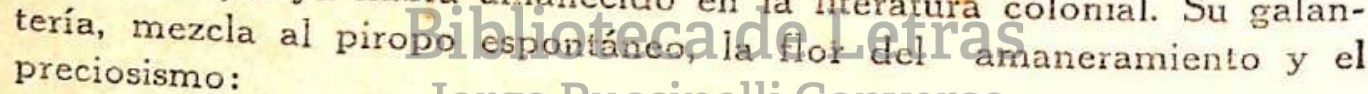

En mis penas inmortales, "Jorge Puccinelli Converso"

sin esperanza padezco,

por ser un achaque amor,

que se cura con el mesmo....

Caviedes, o. c. 429 .

....Muriendo estoy por morix

si contraría me persigue

una voluntad alegre

con una memoria triste....

ibid, 431.

Se lamenta después por la muerte de su esposa y por la vida en precado, y ya, al tono zumbón que zahería médicos, se añade cierto dejo de melancolía, y cierto como engolamiento que acusa el roce con poetas señoriales y de corte. A poco más, este Caviedes, borrachín y antimédico, se inçorpora on una Academia virreinal, en la de 
Castell, en la de Orrantia, que atraían la atención de los rimadores coetáneos.

Pero, ya la mujer ha tocado con su tentación y con su gracia la poesía de Caviedes. Es, ciertamente, el lirismo erótico que nace. Y sin embargo, se ha dicho que el gongorismo amaneció en 1630 . Y pensar que Góngora fué el poeta lírico por excelencia, el lirismo mismo, personificado, hecho carne en un poeta cordobés que alternaba las tareas de racionero catedralicio con la amistad de las musas....

Góngora había sido el lirismo sumo. En él no hay que mirar solo el alambicamiento quitaesenciado y superestético de- las "Soledades" sino tambićn la frescura incomparable de letrillas y romances, de romances y letrillas mal llamados género popular, cuando ya está demostrado hasta la saciedad- y en ello le toca buena parte a José María Cossio, y no poco a Dámaso Alonso y a Alfonso Reyesque el popularismo gongorino fué, estilización de lo vulgar, elevảción a categoría estética de lo tradicional y pueblero. Y en esa sublimación de lo pedestre o poco artístico, surgen los temas femeninos, adueñándose de la inspiración del poeta tánto como los temas clásicos, reminiscencias de lecturas humanistas, huellas de Leda y su cisne enamorado, el mismo cisne y la misma Leda que aparecerían tres siglos más tarde, en los canios de Rubén Dario.

Góngora, Romances, prólogo de José - Ma. Cossio, Madrid, 1927.- id. "Soledades", prólogo de Dámaso Alonso, Madrid, 1927. A Alfonso Reyes, Cuestiones Gongorinas, Madrid, 1927; id. "Cuestiones Estéticas", Paris.- R. Darío, Prosas Profanas; id. "Cantos de Vida y Esperanza.

Pero, con todo, la mujer aparece sutitizadaS Se conoce que a la "vaquera de la Finojosä CartadaepoirCed Marqués, se la tropiezan los poetas y los soldados, en cada vericueto. No existe tortura carnal. No rinde a las voluntades, la urgencia voluptuosa. En el sosiego de conquistas fáciles, Lope puede olvidarse de afilar su lirismo y dedicarse a problemas sociales, conflictos entre el corazón y el trono, entre el deber y la amistad. Y el racionero don Luis, que manejara la espada tan bien como el plectro, bien puede urdir dulces mentiras, disfrazadas entre olas de palabras, para crear un nuevo vehículo poemático, nutrido de humanismo, y al cual dieron algunos inaprensivos en apodar "culteranismo".

En nuestro virreinato ocurre algo semejante, antes de Caviedes. Los primeros poetas son de corte. Siguiendo el módulo italiano se reúnen en derredor de personajes acomodados y tratan de competir en conocimientos. Su lirismo se parece al de Teocrito o al de Virgilio, pero jamás traduce un ansia personal. Los más ilustres vierten al castellano lirismo ajeno. Diego Mexia se vuelve famoso al traducir "Las Heroidas" de Ovidio, y su lirismo retrata las ansias de Onfalia, de Hipólito, de Hécuba, de Fedra, Garcés, tan alabado por Cervantes. encuentra su ruta en los sonetos y canciones de Petrarca y Camoens, 
a quienes traduce e interpreta. Diego Dávalos y Figueroa busca en la marquesa de Pescara y en Tansillo, almas y sentimientos consonantes. Sin embargo, en Dávalos se encuentran ciertos ecos líricos propios. En los primeros Coloquios de su "Miscelánea Austral" (1602) elogia el amor, y alaba la poesía de Ausias March y sus imitadores, para, enseguida, iniciar la "Defensa de Damas" poema en octavas lánguidas, cuyo único valor está precisamente en ser uno de los primeros testimonios de erotismo colonial. Dávalos y Figueroa había salido de su tierra natal, Ecija, en plan de enamorado. Truncóse el idilio repentinamente y le "forzó a perder no solo la dulzura de este amoroso estado, más la alegre vida de mi deleitosa patria".

Dávalos y Figueroa, Miscelanea Austral, Lima 1602, coloquio, 39.- Sánchez, "Diego Dávalos y Figueroa" en "Boletín bibliográfico de la Univ. de S. Marcos, vol. I, n. 7, Lima, abril, 1924.

Hubo un duelo a consecuencia de tales amores, y Dávalos vióse obligado a huir; en la madurez, recordaba aún con harto dolor cómo flameaba, en señal de despedida, el pañuelo de la bienamada, desde la ventana a cuyo lado tantas veces hiciera sonar su rabel de enamorado, mozo y juglar.

\section{ibid. coloquios 40 y 41 .}

Se casó Dávalos en Altoperú. Su lirismo se desbocó en añoranres inmortalizados - relativamente- por los elogios de Cervantes, ipoeta que lo pudo hacer.

Y era natural. Tampoco sobresalieron por su lirismo los rimadores inmortalizados Brelativamente-Cpor Oos elogios de Cervantes, Lope, Diego de Aguilāx yol anónime del 'Discurso en loor de la Poesía". Era literatura señoril. Literatura de gentes saciadas, ahitas de amor, y cuyo lirismo se entretenía en glosas y rapsodias de otros poemas, los de Tasso, Ariosto, Dante, o el lejanísimo y convencional ardor de Diodo al entregarse a Eneas. Buscaban en la antiguedad motivos amorosos que tenían tan cerca.... Sus sentidos no requerían la colaboración celestinesca de la literatura, sino, al contrario, con ésta trataban de idealizar su prosaismo. Los señores tenían siervas; luego, mestizas complacientes y ardorosas. Pero, el pueblo, privado de semejantes deleites, palpitaba de amor. De ahi que vibren de erotismo mal disfrazado, los cantares populares que recoge el folklore. De ahí que en la canción del llamero surja la paloma tierna y voluptuosa; y en la conseja del mestizo, el sexo hable con tánta fuerza. Mestizo fué, sin duda, el que bajo el seudónimo de Concolorcorvo escribió la célebre frase:

"Yo soy indio, salvo las trampas de mi madre de que no salgo fiador. Dos primas mías, coyas, conservan la virginidad, a su pesar, en un convento del Cuzco...." 
Concolorcorvo, Lazarillo de ciegos caminantes, en Guijón

(?), 1773. reed. Buenos Aires, 1908. p. 17.

La mujer era para el poeta virreynal de los principios del seiscientos, una institución respetable. Mujer era la esposa, la señora, la española, la blanca, la igual, la compañera. Hembra, sujeto de placer, era la sierva, la hija de esclavos, la hijastra negada, la hetaira, la complaciente, la amorosa, la querida. La mujer, concebida como dueña, como esposa, dominaba en el hogar. La autoridad del marido no lograba quebrantar la severa regla hogareña. Había una Inquisición vigilante, y, precisamente, a través de los procesos inquisitoriales, se ve cómo la excesiva severidad de la señora, de la matrona, conducía al español hacia la mestiza, más seductora, después. El lirismo académico se nutría, pues, de respeto convencional a la mujer, y disfrazaba sus figuras eróticas en ejemplos mitológicos. El "raptor de Europa" aparece tanto en las "Soledades", gongorinas, como en el engendro llamado "Poema a los 23 mártires del Japón" que compuso el padre limeño Ayllón, allá por el 1630. El fraile Alecio dedica su inspiración a Tomás, llamado "El Angélico" (1645), y cuando aparece la limeña en la "Vida de Santa Rosa" del Conde de la Granja (1712), se la describe con prolija y respetuosa amiración: nada más que admiración. Peralta, sabio encallado en la erudición, no sufre ninguna inquietud carnal o tiene lo que necesita, de donde su obra es toda asexual. Sin impetu, siquiera, de abstinente, ese ímpetu que engendraba teoremas y apotegmas en Newton, y que sólo eyaculó panegíricos y loas en Peralta. En cambio, un arcediano del amanecer del seiscientos, Barco-Centenera, hombre agitado, no ahito, sin posición social elevadoorgeon uprohibición eclessística, siente la atracción poderosa de la mujer, y como le falta depuración, se limita a describirla con parsimonía y delectación malas encubridoras de su apetito insatisfecho.

Véase: Barco Centenera, "La Argentina", Lisboa, 1602, Cantos XXIII-XXV; Ayllón, Poema a los 23 Mártires del Japón, Lima, 1630; Conde de la Granja, Vida de Santa Rosa, Lima, 1712 .

En la Academia de Catell-dos-Rius en la cual participaron los más eximios poetas de entonces, abundan los temas propuestos: la varadura de una ballena en Chorrillos, un concurso de adivinanzas, versos de pie forzado, alabanzas a una lámpara de Palacio, etc.; y muy rara vez la alusión femenina, como si todos estuviesen de acuerdo en desdeñar tema que, en otras latitudes y en otras clases sociales, preocupaba y encendía a los poetas. Apenas si en la segunda sesión se habla de "zagales inconstantes" y pastoras, remiscencias de Virgilio y Garcilaso; y en la quinta, tratan los académicos de loar las bellezas de una mujer con obligadas comparaciones lapidarias: rubíes, 
corales, topacios, diamantes; y es ahí donde Peralta, rompiendo por excepción su habitual severidad, escribe con alguna picardía:

\author{
El ceñido talle efigie \\ cuando verde tela abrocha; \\ tal de esmeralda aguacate \\ que aureo, estrecho, engarce orla; \\ El etcétera es de mármol: \\ que sea de cualquier cosa; \\ pues de lo oculto y vedado, \\ nunca juzga la Helicona. \\ "Flor de Academias", ed. cit. p. 13 y 43.
}

Mas ya por esta época empieza a desatarse la imaginación popular. Caviedes ha sido el primer grito de rebelión. Las mestizas, las trigueñas, que "tienen sin tasa el valor", comienzan a ejercer una dulce tiranía. Los poetas buscan las comparaciones eróticas ya más en la vida que en los libros. Si el Virrey de Nieva muere a resultas de oculto amor, el de Amat trata de ganar con dádivas el favor de las trigueñas, y la Perricholi se ostenta, cono-rena limeña, a fines del setecientos. Contra ella insurge, no el pueblo que la siente suya, sino la nobleza postergada. Son los propios españoles los que aprovechan de la venida de Guirior para attacar a la "Perri" y a su virreinal amante. En el "Diálogo de los Palanganâs" muestra las uñas, por primera vez, la maledicencia capitalina. Pero, eso mismo revela que Amat ha hecho caer una careta. Al relajarelajvigiancie tedesitistica- tan ocupada en si misma- las costumbres cambian La poesía vuelve los ojos a la mujer que se trueca en sueño distante. También la mestiza pone condiciones ahora. $Y \tan$ es así, que el andaluz Terralla y Landa tendrá que esforzarse mucho para alcanzarla, y más todavía para denigrarla, despechado quién sabe por qué inexorable consecuencia de su excesivo erotismo. "Lima por dentro y fuera" resulta así un testimonio de costumbres y una continuación de Caviedes.

Entretanto, en el campo, los hombres para librarse del tributo, de la mita y de la persecusión, se refugian en la soledad. Aquel ascetismo forzado, abstinencia ineludible, conducen al indio al "bestial pecado" de que hablan los teólogos coloniales, y también al canto lírico exasperado.

La ciudad conserva cierto dejo épico, porque se nutre de objetividad. Tiene el burgo un concepto aprehendedor, captor, señorial, de la vida, y en la poesía se refleja así. El campo, en cambio, demuestra una orientación lírica, subjetiva, robinsoniana. La mujer es el ensueño perpetuo de estos célibes obligados cuyo erotismo se confía a la quena, a la liama, a la cumbre. La mujer es la cima hollada, el campo yermo, la cuerda insonora por demasiado familiar, para el 
cantor ciudadano. El del campo no pretende alcanzar canongías y prebendas; el del burgo, sí. El del campo vive, al márgen de la Inquisición, por semibestial; el de la ciudad, tiene sobre él los ojos múltiples del Santo Oficio. Tan es cierto, que hay un momento en que, no obstante ocurrir fenómeno análogo en todo el país, la división se acentúa y se define: la hora de la emancipación.

\section{EROTISMO}

Cuando se inició el ciclo revolucionario, en el Perú se anotaron dos actitudes diferentes:

en la ciudad:

conspiración, criollismo, proclama, charla de café y salón, discursos, poesía, erotismo, epicidad.- Olmedo, Larriva, Riva Aguero.

en el campo:

revolución, algarada, arenga, agitación de cuartel y choza, compromisos, poesía patriótica y limsmo.- Meigar, Sánchez Carrión.

Olmedo y Larriva, los dos panegiristas de María Antonia de Borbón en 1807 y de Abascal en 1806, representan una tendencia epicista, sin ser épica: el lirismo erótico asoma netamente en Melgar. Antes de Melgar, el lirisme se enturbia con resabios chistosistas, algo llamado comunmente sátira, aunque no lo sea. Otros lo mezclaban con el humanismopde tercera mano que usaron los poetas coloniales. Porque es preciso tener en cuenta siemprellaserie de trasbordos su-

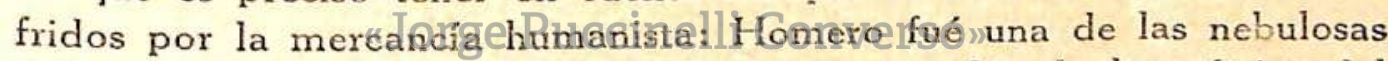
del virreinato. El propio Virgilio, númen tutelar de la métrica del seiscientos y el setecientos, llegó un tanto trunco. Nuestros poetas conocieron a Homero a través de Virgilio, y, a menudo, éste dejó asomar las garras entre las versadas de Tasso, Ariosto y Dante.

Pues, volviendo al tema del lirismo, con Melgar amanece precisamente la lírica erótica. No se puede comparar el modo cómo el amor y la mujer surgen en los demás poetas. Caviedes los presenta de manera cómica, un día; y otro, alambicando conceptos, frases, metáforas, hipérbaton- seguro vehículo gongorino. Terralla tiene un estilo parecido al de Caviedes, pero más calcado que ninguno, de Quevedo. Las mujeres son para él- misógino de la hora undécima y a fortiori- motivos de escarnio y vituperio:

Que ves a una ninfa hermosa de buen talle, lindo cuerpo, con dos vesuvios por ojos, dos etnas, dos mongibelos; que en tí los clava al instante, 
como explicando y diciendo:

tuya soy bien de mi vida, si acaso tienes dinero.

$E$ insiste en la nota sobre las mestizas, que un siglo antes ins:nuara Caviedes:

Que ves a muchas mulatas

destinadas al comercio;

las unas al de la carne,

las otras al de lo mesmo.

Terralla y Landa (firma este libro con el seudónimo de Simón Ayanque), "Lima por dentro y fuera", Lima 1792, Introducción, Romance primero.

Estas notas ácidas distan infinitamente de Melgar. El poeta de los yaravíes sintió hondo la emoción erótica, pero, mientras en Terralla- amador experto y veteramo, a quien la saciedad alejaba de la galantería y el lirismo- la mujer fué un motivo cotidiano, indigno de sublimarlo en un poema, en Melgar, lanmujer fué tentación, enigma, incertidumbre. Seminarista, prematuramente emancipado de la sotana y la tonsura, el mozo Melgar idealizó el fuego que le quemaba la sangre. Consta por los datos concretos que publicó Cúneo-Vidal, la edad de once años en Silviáa cuando la conoció y la cantó Melgar, que ya tenía dieciocho. Practicamente, sólo un esfuerzo de imaginación enorme lograría salvar esta distancia. La chiquilla de once años mal podía despertar una pașôn lefectraa en Gl jaten aS dieciocho, sino a cambio de constatar la circunstanciali de Hna adolescencia seminaril, regada de preces, "y en ra cual fué la mujer-sexuada o asexuada aún -la tentación sublime y abominable, sutil encarnación del Enemigo que así deslumbraba a quienes querían perder. Y Melgar, tensa la voluntad en el esfuerzo de permanecer puro, idealizó a la ignoradia y dulce enemiga, que se vengaba dominándolo de sutil manera.

Ay, Silvia! Si, a lo menos, tú, mi llanto

Pudieras atender y mis sollozos....

Ah, mi acerbo dolor no fuera tanto...

Melgar, Poesías, Lima, 1878, P. 77.-Cúneo Vidal, Reminiscencias de María Santos Corrales, en "Revista hist. vol. VIII, Lima, 1921, p. 5-16.

Queda como rezago de la enseñanza humanista, del seminario, el nombre evocador: Silvia. Queda- eco de férula y disciplina, de afición a la servidumbre; y de los románticos, entrevistos apenas- la amistad con la tristeza. Melgar surge así. Y la nota elegiaca, y la nota lírica, y la nota amatoria, despiertan el lirismo peruano, amasado 
de nostalgia indígena porque este mikimae perdido en la revolución se entrenó para la desventura y la muerte, con la gimnasia del amor imposible.

En Melgar,-Newton sin binomio, Kant si noumeno, José sin capa, Antonio sin desierto- la ausencia de mujer ascendra el erotismo y produce al lírico. La ausencia de mujer y la lírica... Porque no es lirico, sino sencillamente trivial, donjuanesco decir de aquel morboso legislador, poeta en prosa, orador, soñador, amador, Manuel Lorenzo Vidaurre, cuando con sublime ignorancia del ridículo escribe en una página: "Yo tengo la gloria de haber inspirado a los cincuenta y un años de mi edad, una verdadera pasión a la joven más hermosa de mi país".

Vidaurre, "Cartas Americanas", Filadelfia, 1823.

Vidaurre fué un erótico, Melgar un sentimental: produce uno, donjuanismo, el otro lirisno. El donjuân tiene un sentido dinámico y memorialista de la pasión: el poeta, un concepto estático, contemplativo, confidencial. El nemorialismo y la confldencia se parecen mucho, pero no hesta el extremo de identificarse, porgquésta cultiva el tono menor, y rumorea sus palabras, mientras ol otro forja el plinto de una estatua para sí mismo. Maurois ha destilado en agudos párrafos su escepticismo absoluto sobre la sinceridad de los memorialistas.

Maurois, Aspecto de la biographic, Paris, 1928, p. 79.

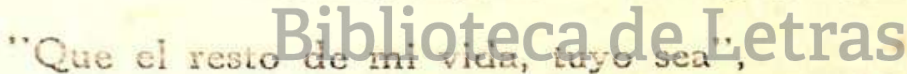

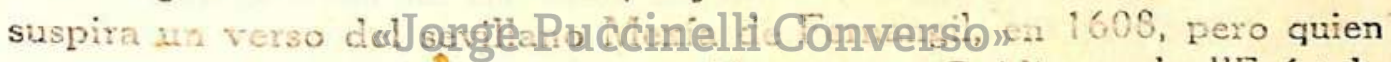
pronuncia el voto amoroso no es Mexía sino Cvilio on la "Epístola de Helena a Paris" de "I as Hercidas" cue el sevillano vertió al español bajo el título de "Parnaso Antártico". Melgar abandona la ficción de amar por boca de personajes mitológicos y desnuda su ascendrada clesesperanza anie la perseguida. Ya surge ahi el masoquismo del amor imposible. Más tarde habrá de quejarse con jactancia,jactancia que trueca la queja en reto,- Chocano en un poema:

"Esto de los amores imposibles, me viene,

como una infausta herencia de mis antepasados".

Chocano, Fiat Lux, París, 1908, p. 133.

Pero, José María Eguren, en quien la superidealización de la mujer trae el recuerdo de Melgar, tendrá amadas irreales: la niña de la lámpara azul, la sombra que cobijó su infancia, personajes vagarosos y dulcemente tentadores como la Stella y la Ligeia de Poe, alquitaramiento de lirismo, desvitalización de la mujer, lirismo purísimo que altema la nota íntimamente erótica, pero pudibunda, con la afición a la galantería oral. 


\section{MUJER: TEMA Y PENATE}

No hubo, por consiguiente, poesía erótica colonial, a menos de llamar así a un género rapsodista de leyendas mitológicąs. Aparece cierto lirismo en algunos poetas como Caviedes, cuando la mestiza empieza a darse a desear y a poner alto su precio; en Melgar, seminarista trunco, prematuramente desviado a la acción política, desasido del amor mismo en su raigambre carnal. Chocano, fabuloso usufructuador de corazones en la vida real, tiene un lirismo discutible-y este es un cuasi mea culpa a cierto elogio que no soy yo quien hace publicar por donde quiera-y la mujer en sus versos no es pasión avasalladora, sino tema de comparación, como en Darío, poligámico y tumultuoso; mientras en Nervo, monógamo, fiel a Anita, la mujer surge no como anécdota-que eso es ya donjuanismo-sino trascendiendo a categoría, más que estética, mística, filosófica, lo cual constituye, indudablemente, una virtualidad lírica neta.

La mujer en la colonia se presentaba en un doble aspecto, que se explica y refleja certeramente en la poesía. Era fácil y dominadora. Lógicamente, el poeta no necesitaba fingírsela con infinitas bellezas, ya que la tenía tan aprehensible y propicia; ni exaltar su poder, puesto que éste existía includablemente. La mujer de raza negra o indígena fué la presa de la lujuria blaḥcat $Q$ ar se desbordabal lirismo que, contenido, habríase manifestado en daiRoeśa lírifa como entre los árabes y como en las grandes etapas místicas, por ejemplo la Edad Media. Más tarde, la mestiza se convirtió en el entretenimiento accesible de los señores. De otro lado, la mujer, la blanca, ejercía autoridad suma en el hogar; mandaba, regía, legislaba en la casa, y no era necesario forzar la imaginación para describir su poderío.

Al pasar los años, la mestiza empezó a cotizar alto sus favores. Ya no era tan fácil el amor. En la casa se resquebrajaba la autoridad materna ante los avances de la instrucción, cuya primera eficacia consistió en introducir un espíritu frondeur, de libre exámen, en el seno mismo de la familia. Lógicamente, los escritores exaltaron más a la mujer difícil ya.

Los que habían ascendrado su erotismo, porque estaban privados de todas las condiciones en que vivían los blancos, fueron los indígenas, los negros, los mestizos. Pero, la imprenta no estaba a su servicio, ni tampoco la instrucción. De donde su lírica derivó, necesariamente, al canto y al baile. Las danzas populares tienen toda la penetrante y expresiva significación de un poema lírico. Son el lirismo dinámico y ondulante. Lirismo que se enturbia de lascivia-así ocurre en el "Cantar de los Cantares"-, en el tango; que escribe con 
el escobilleo de los pies una estrofa encendidísima en la "moza mala" y el tondero; que se subleva bravía e insatisfecha en el taconeo de la cueca; que en el bambuco se desenrosca, perezosamente y que se crispa en la rumba; y en la machicha y el tamborcito desteje diversas fases de la pasión erótica. A falta de imprenta, acude la lírica popular a la memoria de las gentes. Sus cuitas y sus polémicas asoman en el dúo, la payada, el refrán. Lirismo militante, cuando habla de olvido arranca quejas a guitarra, charango o tiple; o ulula en la antara- ¿carrizo pánico?-de catorce tubos.

Es el pueblo, la gente sin cultura, la que, entences, quiere traducir la ausencia de mujer que precipita su lirismo. Mujer ausente o difícil, obliga a que los cantores se afinen, se ascendren, y cada día sea más delicado y sutil la entonación del joropo y el huayno; y el verso aprenda maneras corteses, para requebrar y almibararse con cierta galantería entre salonera y rural.

Más tarde, al llegar la Emancipación, la mujer se siente sujeto jurídico, persona considerada legalmente, capaz de tener otras ocupaciones; y su ausencia-por mil razones, entre otras económicas-produce un exacerbamiento de la lírica, especialmente la romántica. Pero, luego, la evolución social -no solo económica,--trasforma esa ausencia en convivencia; el hetairismo, las nuevas costumbres facilitan las relaciones entre ambos sexos, y el lírismo decae. ¿Podría decirse de la nuestra que es una literatura esencialmente lírico-erótica? Lirismo sabio, cauteloso, premeditado, culto, erudito y cerebral, junto a profunda angustia social, prepcupación económica, discriminación de problemas de justicia; qué distantes de ese lirismo prístino, del romántico y aún del simbolistatorfronteracientel dosnébadesu- cuando, ignorando otras cavilaciones, su única y fundamental incógnita se encerraba en la mujer, el amor y la muerte: tres temas poemáticos, relegados a segundo término, ante el surgimiento de otros nuevos tópicos: el prójimo, la cooperación y la vida.

Luis Alberto Sánchez. 